\title{
Detection of feigned cognitive dysfunction using special malinger tests: a simulation study in naîve and coached malingerers
}

Citation for published version (APA):

Jelicic, M., Merckelbach, H. L. G. J., Candel, I. E. L., \& Geraerts, E. G. (2007). Detection of feigned cognitive dysfunction using special malinger tests: a simulation study in naïve and coached malingerers. International Journal of Neuroscience, 117, 1185-1192. https://doi.org/10.1080/00207450600934697

Document status and date:

Published: 01/01/2007

DOI:

10.1080/00207450600934697

Document Version:

Publisher's PDF, also known as Version of record

Please check the document version of this publication:

- A submitted manuscript is the version of the article upon submission and before peer-review. There can be important differences between the submitted version and the official published version of record.

People interested in the research are advised to contact the author for the final version of the publication, or visit the DOI to the publisher's website.

- The final author version and the galley proof are versions of the publication after peer review.

- The final published version features the final layout of the paper including the volume, issue and page numbers.

Link to publication

\footnotetext{
General rights rights.

- You may freely distribute the URL identifying the publication in the public portal. please follow below link for the End User Agreement:

www.umlib.nl/taverne-license

Take down policy

If you believe that this document breaches copyright please contact us at:

repository@maastrichtuniversity.nl

providing details and we will investigate your claim.
}

Copyright and moral rights for the publications made accessible in the public portal are retained by the authors and/or other copyright owners and it is a condition of accessing publications that users recognise and abide by the legal requirements associated with these

- Users may download and print one copy of any publication from the public portal for the purpose of private study or research.

- You may not further distribute the material or use it for any profit-making activity or commercial gain

If the publication is distributed under the terms of Article $25 \mathrm{fa}$ of the Dutch Copyright Act, indicated by the "Taverne" license above, 
This article was downloaded by:[Universiteit Maastricht]

On: 29 June 2007

[Universiteit Maastricht]

Access Details: [subscription number 772551771]

Publisher: Informa Healthcare

Informa Ltd Registered in England and Wales Registered Number: 1072954

Registered office: Mortimer House, 37-41 Mortimer Street, London W1T 3JH, UK

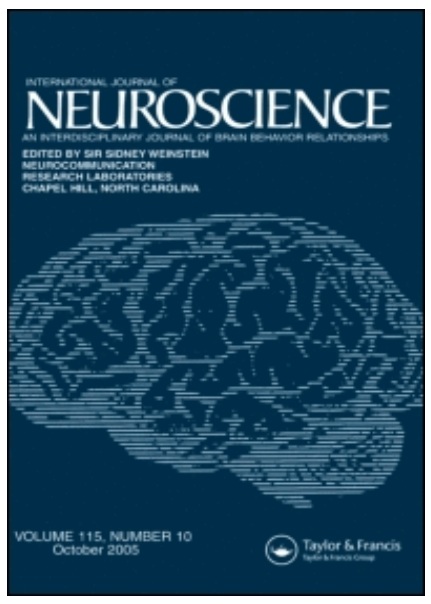

International Journal of Neuroscience

Publication details, including instructions for authors and subscription information: http://www.informaworld.com/smpp/title content=t713644851

DETECTION OF FEIGNED COGNITIVE

DYSFUNCTION USING SPECIAL MALINGER TESTS: A SIMULATION STUDY IN NAÏVE AND COACHED MALINGERERS

Online Publication Date: 01 August 2007

To cite this Article: Jelicic, Marko, Merckelbach, Harald, Candel, Ingrid and Geraerts, Elke , (2007) 'DETECTION OF FEIGNED COGNITIVE DYSFUNCTION USING SPECIAL MALINGER TESTS: A SIMULATION STUDY IN NAÏVE AND COACHED MALINGERERS', International Journal of Neuroscience, 117:8, 1185 1192

URL: http://dx.doi.org/10.1080/00207450600934697

To link to this article: DOI: $10.1080 / 00207450600934697$

\section{PLEASE SCROLL DOWN FOR ARTICLE}

\section{Full terms and conditions of use: http://www.informaworld.com/terms-and-conditions-of-access.pdf}

This article maybe used for research, teaching and private study purposes. Any substantial or systematic reproduction, re-distribution, re-selling, loan or sub-licensing, systematic supply or distribution in any form to anyone is expressly forbidden.

The publisher does not give any warranty express or implied or make any representation that the contents will be complete or accurate or up to date. The accuracy of any instructions, formulae and drug doses should be independently verified with primary sources. The publisher shall not be liable for any loss, actions, claims, proceedings, demand or costs or damages whatsoever or howsoever caused arising directly or indirectly in connection with or arising out of the use of this material.

(C) Taylor and Francis 2007 


\title{
DETECTION OF FEIGNED COGNITIVE DYSFUNCTION USING SPECIAL MALINGER TESTS: A SIMULATION STUDY IN NAÏVE AND COACHED MALINGERERS
}

\author{
MARKO JELICIC \\ HARALD MERCKELBACH \\ INGRID CANDEL \\ ELKE GERAERTS \\ Maastricht University \\ Maastricht, The Netherlands
}

\begin{abstract}
The aim of the present study was to compare the accuracy of the Amsterdam Short Term Memory (ASTM) test with that of the Structured Inventory of the Malingered Symptomatology (SIMS) in detecting feigning of cognitive dysfunction in naïve and coached participants. Ninety undergraduate students were administered the ASTM and the SIMS and asked to respond honestly (controls; $n=30$ ), or instructed to malinger cognitive dysfunction due to head injury. Before the both instruments were administered, naïve malingerers received no further information $(n=30)$, whereas coached malingerers were given some information about brain injury and a warning not to exaggerate symptoms $(n=30)$. Both tests correctly classified $90 \%$ of the naïve malingerers. The ASTM detected $70 \%$ of the coached malingerers, whereas the SIMS continued to detect $90 \%$ of them. The findings suggest that coaching undermines the diagnostic accuracy of the ASTM, but does not seem to influence the accuracy of the SIMS.
\end{abstract}

Keywords brain injury, coaching, forensic neuropsychology, malingering

\section{INTRODUCTION}

The assessment of cognitive status in neurological and psychiatric patients is one of the main tasks of clinical neuropsychologists (Maruish \& Moses, 1997).

Received 17 January 2006.

Address correspondence to Marko Jelicic, Department of Experimental Psychology, Maastricht University, P. O. Box 616, 6200 MD Maastricht, The Netherlands. E-mail: m.jelicic@ psychology.unimaas.nl 
Over the past decades, many neuropsychological tests and questionnaires have been developed to measure various cognitive functions (e.g., memory, attention, executive function). The interpretation of abnormal test scores in hospital patients usually is uncomplicated: poor performance on neuropsychological tests can be regarded an expression of cognitive dysfunction (Lezak et al., 2004). In medical-legal cases, however, the interpretation of abnormal scores on neuropsychological tests often is a difficult issue (Faust, 1996). When financial incentives are at stake, patients may be motivated to aggravate or feign symptoms. On neuropsychological tests, such patients may perform substantially below their actual cognitive capacities. Binder and Rohling (1996) showed that malingering frequently occurs in patients seeking financial compensation after closed-head injury. They performed a meta-analysis on 18 published studies and found that patients with financial incentives exhibit poorer performance on cognitive tests than those who are not involved in litigation. By and large, patients seeking financial compensation perform one-half standard deviation below the other patients. According to Binder and Rohling, a considerable part of the variance in test performance in neuropsychological patients seeking financial compensation can be attributed to malingering.

Different strategies have been proposed to detect malingering in medical-legal cases. Some authors argue that the aggravation and feigning of cognitive dysfunction can be detected by looking at inconsistent test performance (Hartlage, 1998). For example, attention and concentration mediate memory performance. If a patient performs well on memory tests, but poorly on tests of attention and concentration, this would be an indication of malingering. Research, however, has shown that clinicians have great difficulty in detecting malingering. In some experiments, experienced clinical neuropsychologists were given neuropsychological test protocols from several individuals (Faust et al., 1988; Heaton et al., 1978). Some of the protocols were from healthy participants who were instructed to feign cognitive dysfunction, while the others were from patients with genuine brain injury. The clinicians were asked to judge which protocols were indicative of malingering. Although the neuropsychologists were fully informed about the purpose of the experiments, they had great difficulties to distinguish instructed malingerers from genuine patients.

The finding that clinicians have difficulty in detecting malingering has inspired researchers to develop special malinger tests. These tests are usually based on the notion that malingerers have limited knowledge of true neuropsychological symptoms (Larrabee, 2005). Two examples of special malinger tests are the Amsterdam Short Term Memory (ASTM; Schmand 
et al., 1998) test and the Structured Inventory of the Malingered Symptomatology (SIMS; Smith \& Burger, 1997). The idea behind the ASTM is that malingerers do not know that true brain-injured patients perform well on simple recognition tests (Schmand et al., 1998). The rationale behind the SIMS is that malingerers tend to endorse atypical and bizarre symptoms that in the eyes of laypeople may seem to be related to brain damage (Smith \& Burger, 1997).

In the forensic literature, there are clear case descriptions of attorneys who educated their clients about how to feign symptoms of brain injury before the clients underwent neuropsychological evaluations (Youngjohn, 1995; see also Rosen, 1995). Such “attorney coaching” may undermine the accuracy of special malinger tests like the ASTM and the SIMS. Youngjohn et al. (1999) argued that providing malingerers with information about true patients and warning them not to exaggerate symptoms could lead to sophisticated malinger behavior. The present study was initiated to test the idea that "coaching" may reduce the accuracy of the ASTM and the SIMS in detecting feigned memory impairments. It was anticipated that both tests would be able to distinguish between naïve malingerers and control participants, but would lose their diagnostic accuracy when they have to differentiate between coached malingerers and controls.

\section{METHODS}

\section{Participants}

Participants were 90 undergraduate students (29 men) who agreed to take part in a simulation experiment in return for a small financial compensation (approximately 6 US $\$$ ). The experiment was approved by the standing ethical committee of the Faculty of Psychology (Maastricht University). Mean age was 21 years $(S D=2.0$; range $18-27$ years $)$. Participants were randomly assigned to one of the three groups.

\section{Materials}

Participants were administered the ASTM (Schagen et al., 1997; Schmand et al., 1998) and the SIMS (Smith \& Burger, 1997; Merckelbach \& Smith, 2003). The ASTM (Schmand et al., 1998) consists of 30 items. In each item the participant is presented with 5 printed words from the same semantic category (e.g., apple, peach, grape, pear, banana), which she or he has to read aloud and try to remember. Next, the participant is given a simple written addition or subtraction task (e.g., $27+15=$ ), which she or he has to solve mentally. Finally, 
5 words from the same semantic category as before are presented (e.g., apple, grape, melon, peach, kiwi). The participant has to indicate the 3 words that were also presented in the first series. The maximum score is 90 (30 items $\times 3$ words correct). Scores below 86 points are considered to be indicative of aggravation or feigning. Contrary to laypeople's expectation, this task does not involve effortful retrieval from memory. As a result, patients with moderate head injury will perform well on this test (ASTM scores usually ranging from 87 to 90). The SIMS (Smith \& Burger, 1997) is a self-report measure designed to screen for malingering in five domains: low intelligence, affective disorders, neurological impairment, psychosis, and amnesia. It consists of 75 yes-no items. The items on the SIMS refer to bizarre (e.g., "I cannot remember whether or not I have been married") and atypical (e.g., "When I can't remember something, hints do not help") symptoms and complaints. After re-scoring reversed items, a total SIMS score can be obtained by summing yes-answers (i.e., endorsement of atypical or bizarre symptoms). Total scores range from 0 to 75 . Scores exceeding the cut-off of 14 are regarded to be indicative of malingering.

\section{Procedure}

Because the experimenter was blind for the three conditions, participants were given an envelope containing the instructions. In the control group $(n=30)$, participants were asked to do their best on the tests and to fill out the questionnaire honestly. In the naïve malinger group $(n=30)$, participants were given a scenario about an accident in which they sustained a head injury, and they were asked to act as though they had deficits resulting from that accident. These participants were specifically instructed to fake or exaggerate symptoms of brain injury in a believable way. In the coached malinger group $(n=30)$, participants received the same scenario, but this time they were also provided with information about cognitive dysfunction after head injury. Furthermore, they were warned not to exaggerate their symptoms. The scenario and instructions were taken from Suhr and Gunstad (2000). Participants in the three groups completed both the ASTM and the SIMS, but the order of the tests was counterbalanced within each group.

\section{RESULTS}

Mean total ASTM and SIMS scores of the three groups are presented in Table 1. One-way Analysis of Variance (ANOVA) showed significant differences in ASTM scores between the three groups $[F(2,87)=29.9 ; p<.001]$. Post-hoc 
Table 1. Mean scores (SD) on the Amsterdam Short Term Memory (ASTM) Test and Structured Inventory of Malingered Symptomatology (SIMS) of participants in the three groups (each containing $n=30$ )

\begin{tabular}{lccc}
\hline & $\begin{array}{c}\text { Control } \\
\text { participants }\end{array}$ & $\begin{array}{c}\text { Naïve } \\
\text { malingerers }\end{array}$ & $\begin{array}{c}\text { Coached } \\
\text { malingerers }\end{array}$ \\
\hline ASTM & $88.1(1.6)$ & $68.4(14.0)$ & $77.3(9.7)$ \\
SIMS & $5.0(3.3)$ & $30.3(11.2)$ & $25.5(10.4)$ \\
\hline
\end{tabular}

analyses using Student-Newman-Keuls tests demonstrated that participants in the control group had higher ASTM scores than those in the two malinger groups, while participants in the coached malinger group had higher scores than those in the naïve malinger group (all $p \mathrm{~s}<.01$ ). An ANOVA also indicated significant differences in SIMS scores between the three groups $[F(2,87)=$ $66.3 ; p<.001]$. Post-hoc comparisons using Student-Newman-Keuls tests showed that participants in the control group had lower SIMS scores than those in the two malinger groups (all $p \mathrm{~s}<.001$ ). There were no reliable differences in SIMS scores between the two malinger groups.

Table 2 shows the number (and percentage) of participants in each group that were correctly classified as honest responders or malingerers on the basis of the ASTM or SIMS cut-offs. As can be seen, $90 \%$ of the naïve malingerers and $70 \%$ of the coached malingerers were correctly identified by the ASTM (sensitivity). The difference in detection rate between naïve and coached malingerers was borderline significant, $\chi^{2}(1)=3.75, p=.05$. In addition, $90 \%$ of the control participants were correctly classified as non-malingerers (specificity). As for the SIMS, in both malinger groups, $90 \%$ of the participants were correctly classified (sensitivity). All control participants (100\%) were correctly identified as honest responders.

Table 2. Number (and percentage) of participants in the three groups (each containing $n=30$ ) correctly classified by the Amsterdam Short Term Memory (ASTM) Test and the Structured Inventory of the Malingered Symptomatology (SIMS)

\begin{tabular}{lccc}
\hline & $\begin{array}{c}\text { Control } \\
\text { participants }\end{array}$ & $\begin{array}{c}\text { Naïve } \\
\text { malingerers }\end{array}$ & $\begin{array}{c}\text { Coached } \\
\text { malingerers }\end{array}$ \\
\hline ASTM & $27(90 \%)$ & $27(90 \%)$ & $21(70 \%)$ \\
SIMS & $30(100 \%)$ & $27(90 \%)$ & $27(90 \%)$ \\
\hline
\end{tabular}




\section{DISCUSSION}

The results of the present study can be easily summarized. The ASTM was able to detect $90 \%$ of the naïve malingerers. This percentage dropped to $70 \%$ in the coached malinger group. Coaching therefore seems to undermine the accuracy of the ASTM. Also, the ASTM produced a non-trivial percentage of false positives: $10 \%$ of the controls were incorrectly classified as malingerers. In contrast, the SIMS did not produce any false positives: all controls were correctly identified as honest responders. Furthermore, the SIMS correctly identified $90 \%$ of the naïve malingerers. This $90 \%$ detection level was maintained in the group of the coached malingerers. Thus, it seems that the SIMS is relatively resistant to the effects of coaching.

The present findings are partly in line with the suggestion of Youngjohn et al. (1999) that coaching leads to more sophisticated forms of malingering. Coaching did have an effect on the ASTM, but did not undermine the efficacy of the SIMS. Although the ASTM and the SIMS are both based on the idea that malingerers have little knowledge of genuine cognitive dysfunction, they differ in one important aspect. The ASTM is a performance test, whereas the SIMS is a self-report tool containing atypical and bizarre items. Many experts assume that self-reports are highly sensitive to the corruptive influence of coaching (Lees-Haley, 1990), but at minimum the present results demonstrate that specialized malinger self-reports such as the SIMS are not necessarily more sensitive to coaching than are performance measures. It should be noted here that performance-based malinger tests such as the Test of Memory Malingering (TOMM; Powell et al., 2004) and the Word Memory Test (WMT; Gervais et al., 2001) do appear to be relatively immune to the effects of coaching. Clearly, more systematic research on the effects of coaching on a broad range of performance-based and self-report malinger tests is necessary. The SIMS data suggest that even warned participants with some knowledge of neurological symptoms are most of the time unable to mimic the exact features of brain injury.

Three issues deserve some comment here. First, the participants were not extensively coached. They were provided with some background information about the effects of brain injury, and warned not to exaggerate their symptoms. Yet, the rationale behind the malinger tests was not explained to them. Thus, in forensic practice, there is still a chance that malingerers who underwent extensive attorney coaching are able to beat the ASTM and the SIMS. This, of course, requires attorneys who know the principle behind malinger tests. Second, the current study used a simulated malingering design. It may well be that, 
in medical-legal cases, individuals who are aggravating or feigning cognitive dysfunction are more cautious than instructed malingerers. Third, in the present study, the base rate of malingering was set at $66 \%$, which is, of course, unrealistically high. However, as Rosenfeld et al. (2000) showed in their thoughtful review, the diagnostic accuracy on instruments might drastically change when base rates become lower. This is an issue that deserves further study. Notwithstanding these limitations, the present findings suggest that, although the ASTM is affected by information about brain injury and a warning not to exaggerate, the SIMS appears to be relatively resistant to the effects of coaching.

\section{REFERENCES}

Binder, L. M., \& Rohling, M. L. (1996). Money matters: A meta-analytic review of the effects of financial incentives on recovery after closed-head injury. American Journal of Psychiatry, 153, 7-10.

Faust, D. (1996). Assessment of brain injuries in legal cases: Neuropsychological and neuropsychiatric considerations. In B. S. Fogel, R. B. Schiffer, \& S. M. Rao (Eds.), Neuropsychiatry. (pp. 973-990). Williams \& Wilkens: Baltimore.

Faust, D., Hart, K. J., \& Guilmette, T. J. (1988). Pediatric malingering: The capacity of children to fake believable deficits on neuropsychological testing. Journal of Consulting and Clinical Psychology, 56, 578-582.

Gervais, R. O., Green, P., Allen, L. M., \& Iverson, G. L. (2001). Effects of coaching on symptom validity testing in chronic pain patients presenting for disability assessments. Journal of Forensic Neuropsychology, 2, 1-19.

Hartlage, L. C. (1998). Clinical detection of malingering. In C. R. Reynolds (Ed.), Detection of malingering during head injury litigation: Critical issues in neuropsychology. (pp. 239-260). New York: Plenum.

Heaton, R. K., Smith, H. H., Lehman, R. A., \& Vogt, A. T. (1978). Prospects for faking believable deficits on neuropsychological testing. Journal of Consulting and Clinical Psychology, 46, 892-900.

Larrabee, G. J. (2005). Forensic neuropsychology: A scientific approach. New York: Oxford University Press.

Lees-Haley, P. R. (1990). Malingering mental disorder on the Impact of Event Scale: Toxic exposure and cancerphobia. Journal of Traumatic Stress, 3, 315-321.

Lezak, M. D., Howieson, D. B., \& Loring, D. W. (2004). Neuropsychological assessment. 4th edn. New York: Oxford University Press.

Maruish, M. E., \& Moses, J. A. (1997). Clinical neuropsychology: Theoretical foundations for practitioners. Mahwah, NJ: Lawrence Erlbaum.

Merckelbach, H., \& Smith, G. P. (2003). Diagnostic accuracy of the structured inventory of malingered symptomatology (SIMS) in detecting instructed malingering 18 , 145-152. 
Powell, M. R., Gfeller, J. D., Hendricks, B. L., \& Sharland, M. (2004). Detecting symptom- and test-coached simulators with the Test of Memory Malingering. Archives of Clinical Neuropsychology, 19, 693-702.

Rosen, G. M. (1995). The Aleutian enterprise sinking and posttraumatic stress disorder: Misdiagnosis in clinical and forensic settings. Professional Psychology: Research and Practice, 26, 82-87.

Rosenfeld, B., Sands, S. A., \& Van Gorp, W. G. (2000). Have we forgotten the base rate problem Archives of Clinical Neuropsychology, 15, 349-359.

Schagen, S., Schmand, B., De Sterke, S., \& Lindeboom, J. (1997). Amsterdam Short Term Memory test: A new procedure for the detection of feigned memory deficits. Journal of Clinical and Experimental Neuropsychology, 19, 43-51.

Schmand, B., Lindeboom, J., Schagen, S., Heijt, R., Koene, T., \& Hamburger, H. L. (1998). Cognitive complaints in patients after whiplash injury: The impact of malingering. Journal of Neurology, Neurosurgery and Psychiatry, 64, 339-343.

Smith, G. P., \& Burger, G. K. (1997). Detection of malingering: Validation of the Structured Inventory of Malingered Symptomatology. Journal of the American Academy of Psychiatry and the Law, 25, 183-189.

Suhr, J. A., \& Gunstad, J. (2000). The effects of coaching on the sensitivity and specificity of malingering measures. Archives of Clinical Neuropsychology, 15, 415-424.

Youngjohn, J. R. (1995). Confirmed attorney coaching prior to neuropsychological evaluation. Assessment, 2, 279-283.

Youngjohn, J. R., Lees-Haley, P. R., \& Binder, L. M. (1999). Comment: Warning malingerers produces more sophisticated malingering. Archives of Clinical Neuropsychology, 14, 511-515. 